\title{
Inguinal Hernia: The Quest for the Best Repair
}

\author{
Ismaila BO FWACS, Misauno MA FWACS, Ojo EO FMCS \\ Department of Surgery, Jos University Teaching Hospital, Jos Plateau State, Nigeria
}

\begin{abstract}
Background: Inguinal hernia repair may be the most common procedure in general surgery. Many repairs have been described but none appears completely satisfactory. A brief look at the popular methods of repair from the traditional tissue approximation to the current meshbased techniques is presented.
\end{abstract}

Methods: The PubMed database was searched for all English language literature. Further references were obtained through cross-referencing the bibliography cited in each work and using books from the authors' collection.

Conclusion: The history of inguinal hernia is a rich one, from the traditional tissue approximation techniques to the current mesh-based repairs which are now performed as open or laparoscopic procedures. Recurrent rates have reduced but are still a problem. Perhaps the perfect repair remains elusive because the problem may also be with patients' collagen not just the surgical procedure.

Keywords: Inguinal hernia, repair, tissue approximation, mesh

\section{Date Accepted for Publication: $15^{\text {th }}$ June 2010 NigerJMed 2010: 369-373 \\ Copyright@2010 Nigerian Journal of Medicine8}

\section{Introduction}

Hernia, derived from the Greek word Hernos (branch or protrusion) has been recognized for centuries and reference to its occurrence and treatment by trusses and girdles is found in early Egyptian, Chinese, and Phoenician writings with Hippocrates describing it in detail in 400BC 1 .

Inguinal hernia repair may be the most common procedure performed in general surgery ${ }^{2}$. In United States, it is estimated that 800000 repairs are performed annually. ${ }^{3}$. In the United Kingdom $0.14 \%$ of the population have inguinal hernias for which 70000 operations are performed annually. National inguinal hernia repair statistics for Nigeria are unavailable. Over 80 methods of repair of inguinal hernia have been described since $1887^{5}$. Adequate repair is dependent on a good knowledge of anatomy of the inguinal region. The decision about how to repair hernia is not based on well defined processes, but on tradition, context, and familiarity with the type of hernia.
Earlier described repairs involve manipulation and apposition of tissue around the hernia and result in tension which is blamed for the relatively high recurrent rates. The emphasis now is repair without tension; this has resulted in the widespread use of meshes. Recurrence which has been a major issue in hernia repair depends largely on the experience of the surgeon and the type of repair performed. Recurrence rates for primary repair vary from $1-5 \%$ for hernia specialists and between 5 and $20 \%$ for non specialists. This article is an overview of the history of inguinal hernia repair highlighting the popular methods.

\section{Traditional tissue approximation repairs}

Marcy, a student of Joseph Lister is credited with the first documented attempt at hernia repair described in 1871. He used catgut treated with phenol in a twosuture technique to close the internal ring ${ }^{7,8}$.

Edoardo Bassini, in 1884 made his hallmark description of inguinal hernia repair. His original description involved reconstruction of the posterior wall after cutting the transversalis fascia by incorporating it with internal oblique and transversus abdominis to form a 'conjoint' triple layer, which he sutured to the inguinal ligament with interrupted silk sutures. This resulted in a three layer reinforcement of the posterior inguinal wall ${ }^{9}$. He also established the principle of repairing the posterior wall after dealing with the sac by dissecting the cremaster muscle. Recurrence rate after 1 year was $2.7 \%{ }^{10}$. Bassini is regarded as the pioneer that developed an anatomical repair with clear scientific principles and set the trend for the traditional hernia repairs. His work was adopted but soon modified in different ways ${ }^{11}$, his method of reconstructing the posterior wall was abandoned and commonly the conjoint tendon was just approximated to the inguinal ligament. William Halsted modified Bassini's repair by additionally suturing the external oblique aponeurosis to the inguinal ligament to reinforce the posterior wall, with the spermatic cord placed subcutaneously ${ }^{12}$ but later modified it by placing the cord under the external oblique $^{13}$. 
Chester McVay's modification of Bassini's method in 1942 (McVay or Cooper ligament repair) was to incise and suture the transversalis fascia to the pectineal ligament. He considered this a more anatomical repair based on human cadaver dissections, that transversus abdominis and transversalis fascia inserts into pectineal ligament not inguinal ligament. It enables repair of indirect, direct and femoral hernias ${ }^{14}$. He also popularized the use of relaxing incision to reduce tension ${ }^{14}$.

E.E. Shouldice in 1945 advanced the tissue approximation repairs that had been described previously, by dividing and overlapping the transversalis fascia in a multilayered closure using continuous monofilament suture in 4 suture lines. First suture line overlaps the fascia by suturing the underside of the medial flap to the lateral edge of divided transversalis fascia, while the second suture line approximates the edge of medial flap (transversalis fascia, internal oblique and transverses abdominis muscles to inguinal ligament. The third suture line approximates the medial flap muscles to external oblique aponeurosis and returns as the fourth, further approximating these muscles more superficially to the aponeurosis. ${ }^{14}$ The recurrent rates in hernia specialist centres have been low ${ }^{2,14,15,16,}$ but difficult to replicate elsewhere ${ }^{17,18}$.

Relaxing incisions on rectus sheath first described by Wolfler and Berger (1892 and 1902 respectively) ${ }^{19}$ may be required in the traditional repairs to reduce tension. The commonly used ones were described by Halsted ${ }^{10}$ and Tanner $^{20}$

Fruchard in 1956 described the myopectineal orifice which is bounded by arching fibres of internal oblique superiorly, anterior border of iliac bone inferiorly, rectus muscle medially, and iliopsoas with iliopectineal arch laterally. It is divided into superior and inferior aspects by the inguinal ligament. This orifice allows passage of the spermatic cord superiorly and femoral vessels inferiorly and can be further divided into medial, lateral and femoral triangles which are potential sites of herniation (figure 1) ${ }^{19,21,22}$. Rives and Stoppa developed the posterior preperitoneal approach to hernia repair based on this work.

Moloney's nylon darn is a cheap and effective method of hernia repair with low recurrence rates $(0.8 \%)$ in the original series ${ }^{23,24}$. It involves the placement of nylon 1 from the conjoint tendon to the inguinal ligament without tension, in an interwoven manner ${ }^{25}$. High recurrence rates from the other repairs led to it development ${ }^{25}$. It is not a mesh repair but simulates one and cannot be strictly regarded as a tissue approximation repair. Some randomized control trials have shown similar results between nylon darn and mesh repairs ${ }^{25,26}$ but nylon darn repairs are cheaper ${ }^{26}$.This method of repair was not included in recent reviews of inguinal hernia repair ${ }^{14,22,27}$.

\section{Sutures}

Different hernia repair techniques have employed a variety of suture types- absorbable, non absorbable, natural and synthetic, from catgut to stainless steel ${ }^{28-32}$. Monofilaments have the advantages of strength, good tissue compatibility and are associated with less incidence of infection at the expense of poorer handling properties. Monofilament nylon has been a widely used suture $^{32}$. Braided sutures have been associated with a higher incidence of infections ${ }^{30}$.

\section{Mesh repair}

Early in the twentieth century due to relatively high recurrent rates from repairs by suture approximation, tissue grafts like skin dermis and fascia lata were used for repairs of large, complicated or recurrent hernias including inguinal hernias. These either lacked adequate supporting tissue or could not be closed without excess tension ${ }^{33,}{ }^{34}$. However complications associated with use of tissue grafts included lateral tearing of fascia and cyst formation ${ }^{33,35,36}$.

Different prosthetic materials like tantalum gauze and fortisan fabric had been used in the repair of hernia to induce fibrosis, but were not satisfactory. Tantalum gauze for example, could fragment and be extruded cutaneously ${ }^{37}$.

Although the first mesh repair was performed in 1958 by Usher et al using Marlex mesh (polypropylene) ${ }^{38}$, it was Lichtenstein's tension-free repair which was described in 1986 that introduced a new dawn in inguinal hernia repair. This repair was easy to perform and local anaesthesia could be used. The inguinal canal is exposed using an anterior approach and after any indirect sac or direct hernia is tackled, the posterior wall is strengthened by sewing a piece of polypropylene mesh to the conjoint tendon and the edge of the inguinal ligament. The mesh is slit laterally to accommodate the cord. Recurrences are low (0.5\%) and results have been reproducible ${ }^{39-42}$.

More recent mesh based repairs include Gilbert's description of a posterior repair through an anterior approach without use of sutures. A triangular plug of polypropylene is placed into the preperitoneal space through the internal ring to cover the myopectineal orifice $^{22,43}$. Further development of Gilberts umbrella 
plug has resulted in the Prolene Hernia System which consists of an onlay and underlay patch with a connector in between (figure 2). The underlay patch is supposed to protect all the triangles of the groin with the onlay part reinforcing the medial and lateral triangles while the connector allows correct positioning, prevents migration and protects the internal ring ${ }^{22}$.

Kugel technique uses a bilayer of polypropylene patch with a self-retaining outer memory recoil ring that is placed through a small muscle-splitting incision. The mesh supposedly is in the same place as a preperitoneal repair by laparoscopy. He had a recurrence rate of $0.4 \%$ from 1,468 repairs ${ }^{44}$ but similar results have not been reproduced by others and the procedure is difficult to master ${ }^{22}$.

The plug and patch technique was described in 1993. Here a plug of polypropylene mesh is placed through the defect in the internal ring or posterior inguinal wall with or without an additional flat overlay mesh. It is a simple procedure and can be done under local anaesthesia ${ }^{22}$. It can cause patient discomfort, and complications which are rare include mesh migration ${ }^{45}$. The technique compares favourably with Lichtenstein but is more expensive ${ }^{46}$.

The common laparoscopic repairs that have been described include transabdominal preperitoneal repair (TAPP) and total extraperitoneal repair (TEP) and are based on the principle of placing a mesh in the preperitoneal space as described originally by Stoppa ${ }^{47}$. TAPP is done from within the peritoneal cavity and peritoneum is incised and mesh placed. In TEP all the dissection is within the extraperitoneal space. Effective laparoscopic repair should include dissection of myopectineal orifice and exposure of the pubic bone; excision of fat from cord and preperitoneum; assessment of all possible hernia sites; reduction of direct inguinal hernia; dissection, separation and reduction of indirect sac from cord structures ${ }^{22}$. Trials done comparing open and laparoscopic hernia repair have been controversial ${ }^{48-}$ ${ }^{50}$. The general trend of studies done comparing open and laparoscopic use of mesh for inguinal hernia suggests that laparoscopic repair took longer time, was associated with rare but more serious complications, was more expensive, and had a steeper learning curve. However it caused less chronic pain for patients who returned to work faster. Long term recurrent rates were similar for both, but laparoscopic groin hernias were better repaired by experts. Laparoscopic repair of bilateral groin hernias may be better especially when recurrent ${ }^{51}$.
With improved recurrence rates from mesh repair, chronic groin pain (inguinodynia) defined as post operative pain lasting more than 3 month $^{52}$ is now a problem. Non degradable meshes can also be complicated by infection ${ }^{53,54}$ especially when used in potentially contaminated surgical fields ${ }^{55}$. This has resulted in the trial of biological materials which some studies suggest may give similar results with meshes but with less pain ${ }^{56}$. However evaluation of use of absorbable and biosynthetic materials for inguinal hernia repair have not lived up to initial expectations ${ }^{57}$.The ideal mesh should have no adhesion potential, excellent tissue integration, good memory; shrink minimally, easy to use and cheap. It should also not promote infection, formation of fistula or seroma $^{58}$. The search for the ideal mesh continues.

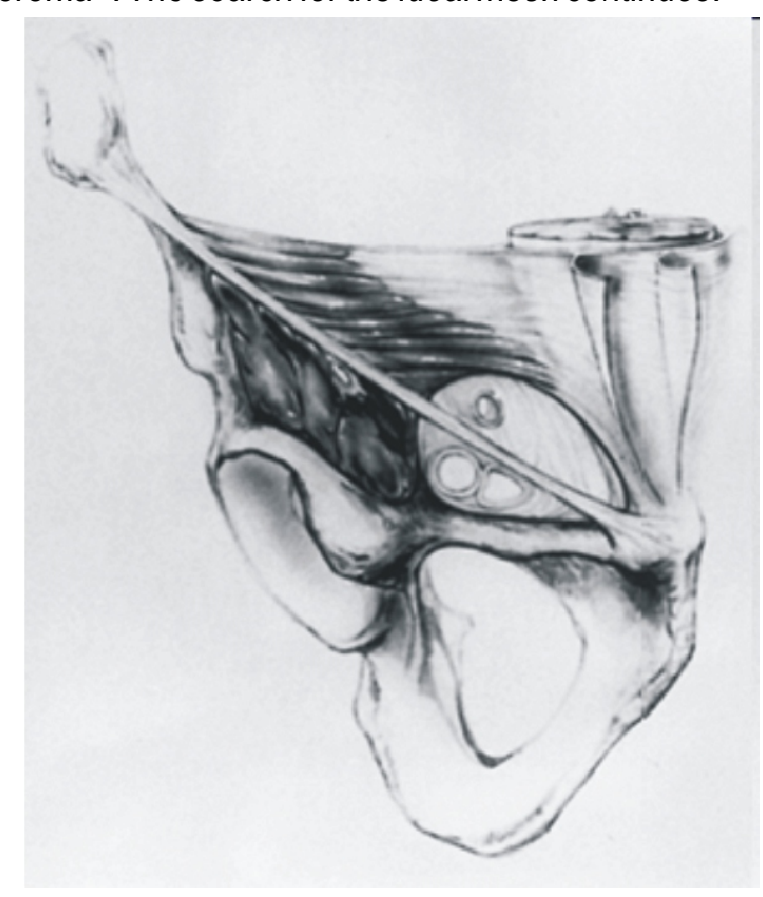

Figure 1 Myopectineal orifice ${ }^{19}$

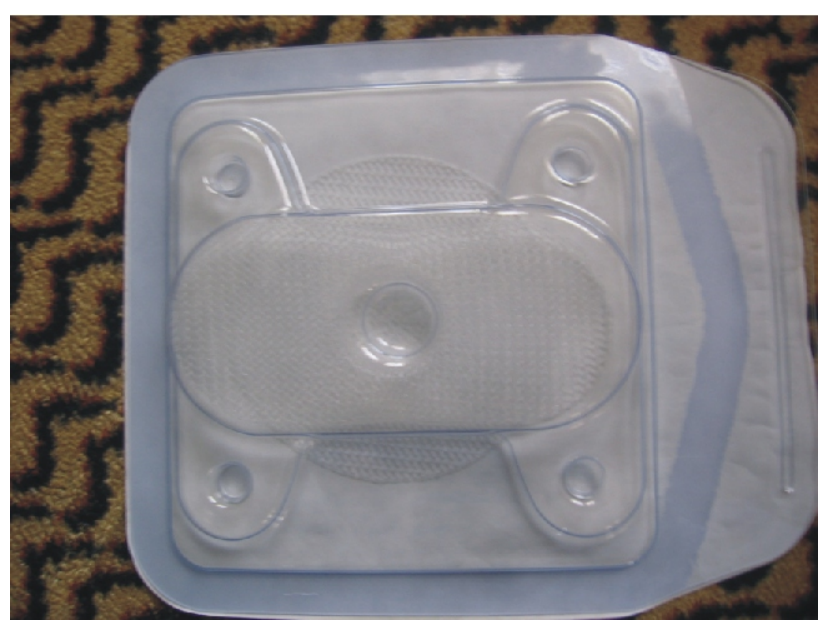

Figure 2 Prolene Hernia System 


\section{Role of collagen}

There is now increasing recognition that the aetiopathogenesis of inguinal hernia may involve changes in the components of the extracellular matrix resulting in less resistance and elasticity of the transversalis fascia ${ }^{59}$. The presence of appropriate type of collagen in adequate amount is essential in normal function of transversalis fascia $^{60.62}$. A normal functioning transversalis fascia is necessary to prevent inguinal hernia and is important in repair ${ }^{63}$. Although mesh repair reinforces and replaces the local tissue, an intrinsically abnormal connective tissue will still be vulnerable to recurrence.

\section{References}

1. Beattie AD. Inguinal Hernia Repair: An analysis of a personal series of 481 cases carried out by modified Bassini Technic Ann Surg 1963; 152: 244-53

2. Schumpelick V, Wantz GE. Inguinal Hernia Repair. Expert meeting on hernia surgery, St Moritz. 25 February 1994. Karger: Basel, 1995

3. Rutkow IM. Demographic and socioeconomic aspects of hernia repair in the United States in 2003. Surg Clin North Am 2003;83: 1045-51

4. National Institute for Health and Clinical Excellence (NICE). Laparoscopic Surgery for Inguinal Hernia Repair. NICE: London, 2004

5. Bendavid R. New techniques in hernia repair. World J Surg 1989; 13: 522-31

6. Deysine M, Soroff HS. Must we specialize herniorrhaphy for better results? Am J Surg 1990; 160: 239-41

7. Griffith CA. The Marcy repair of indirect inguinal hernia. Surg Clin North Am 1971;51:1309-16

8. Read RC. Preperitoneal herniorrhaphy: a historical review. World J Surg 1989;13:532-9

9. Bassini E. New technique for the cure of inguinal hernia [in Italian]Atti CongrAssoc Med Ital 1887;2:179-82

10. KoontzAR, Hernia. New York: Appleton-Century-Croft; 1963

11. Read RC. The development of inguinal herniorrhaphy. Surg Clin North Am 1984;64: 185-194

12. Halsted WS. The radical cure of hernia. Johns Hopkins Hosp Bull. 1889;1:12-13

13. Halsted WS. The cure for the more difficult as well as the simpler inguinal ruptures. Johns Hopkins Hosp Bull. 1903;14:208-214

14. Banks SB, Cotlar MA. Classic groin hernia repair...Lest we forget. Curr Surg 2005; 62: 249-252

15. Devlin HB, Gillen PHA, Waxman BP, MacNay RA. Short stay surgery for inguinal hernia: experience of the Shouldice operation, 1970-1982 Br J Surg; 73: 123-4.

\section{Conclusion}

The history of inguinal hernia repair is a rich one, and currently outcomes have improved. Bassini laid the foundation upon which others have built. Mesh use is established and laparoscopic repair is becoming popular. Recurrence rates are reducing and chronic pain is now an issue. But with the increasing recognition of the role of an abnormal extracellular matrix, perhaps the perfect repair for inguinal hernia may not be within the realms of surgery.

16. Glassow F. The Shouldice Hospital technique. Int Surg 1986; 71: 148-53

17. Kingsnorth AN, Gray MR, Nott DM. Prospective randomized trial comparing the Shouldice and plication darn for inguinal hernia. Br J Surg 1992; 79: 1068-70

18. Tran VK, Putz T, Rhode H. A randomized controlled trial for inguinal hernia to compare the Shouldice and the BassiniKirschner operation. Int Surg 1992; 77: 235-7.

19. Bendavid R. The Shouldice method of inguinal herniorrhaphy. In Fischer JE ed Mastery of Surgery Vol 2. Lippincott Williams and Wilkins, 2007:1889-98

20. Tanner CN. A 'slide' operation for inguinal and femoral hernia. Br J Surg 1942; 155: 285-9

21. Fruchard H. Anatomie Chirurgicale des Hernies de L'Aine. Paris: G. Doin, 1956

22. Awad SS, Fagan SP. Current approaches to inguinal hernia repair. Am J Surg 2004; 188 Supp 9s-16s

23. Moloney GE, Gill WG, Barclay RC. Operations for hernia: technique of nylon darn. Lancet 1948; ii:45-8

24. Moloney GE. Results of nylon darn repairs of herniae. Lancet 1958; i: 273-8

25. Koukourou A, Lyon W, Rice J, Wattchow DA. Prospective randomized trial of polypropylene mesh compared with nylon darn in inguinal hernia repair. Br J Surg 2001; 88: 931-4

26. Chakraborty S, Mukherjee A, Bhattacharya M. Tension-free inguinal hernia repair comparing 'darn' with 'mesh': A prospective randomized controlled clinical trial. Indian J Surg 2007; 69:52-6

27. Campanelli G, Canziani M, Frattini F, Cavalli M, Agrusti S. Inguinal hernia: State of the art. Int J Surg 2008; 6: S26-S28

28. Bracey DW. Inguinal hernia a preliminary communication of a new method of repair. Ann R Coll E

29. Glassow $F$. The surgical repair of inguinal and femoral hernias Can Med Ass J 1973; 108: 308-313 
30. Jones DJ. Inguinal hernia repair: which suture? Ann R Coll Surg Engl 1986;68:323-5.

31. Jayasekara G. Inguinal hernia repair: which suture? Ann R Coll Surg Engl 1988;70:113.

32. Cahill J, Northeast DA, Jarret PE, Leach RD. Sutures for inguinal herniorrhaphy a comparison of monofilaments with PTFE. Ann R Coll Surg Engl 1989; 71: 128-130

33. Eisele WM, Starkloff GB. The use of skin grafts in hernia repair. Ann Surg 1953; 134: 897-903

34. Hamilton JE. Repair of large or difficult hernias with mattressed onlay grafts of fascia lata: A 21-year experience. Ann Surg 1968; $167: 85-90$

35. Strahan AWB. Hernia repair by whole skin grafts with report on 413 cases. Br. J. Surg 1950, 38, 276-284.

36. Rutter AG. Cyst formation seven years after a cutis graft repair of hernia BMJ 1955April

37. Koontz AR, Kimberly RC. An evaluation of the usefulness of fortisan fabric in hernia repair. Ann Surg 1954; 189: 644-9

38. Usher FC, Ochsner J, Tuttle LL Jr (1958) Use of Marlex mesh in the repair of incisional hernias. Am Surg 24:969974

39. Lichtenstein IL, Shulman AG. Ambulatory outpatient hernia surgery. Including a new concept: introducing tension-free repair. Int Surg 1986; 71:1-4

40. Lichtenstein IL, Shulman AG, Amid PK, Montllor MM. The tension-free hernioplasty. Am J Surg 1989; 157: 188-93

41. Shulman AG, Amid PK, Lichtenstein IL. The safety of mesh repair for primary inguinal hernias: results of 3019 operations from five diverse surgical sources. Am Surg1992; 58: 255-7

42. EU Hernia Trialists Collaboration. Repair of groin hernias with synthetic mesh: meta analysis of randomized control trials. Ann Surg 2002; 235:322-32

43. GilbertAL. Sutureless repair of inguinal hernia. Am J Surg 1992; 163: $331-5$

44. Kugel RD. The Kugel repair for groin hernias. Surg Clin N Am 2003; 83: 1119-39

45. Dieter RA Jr. Mesh plug migration into scrotum: a new complication of hernia repair. Int Surg 1999; 84: 57-59

46. Kingsnorth AN, Porter CS, Bennet DH, et al. Lichtenstein patch or Perfix plug-and-patch in inguinal hernia: a prospective double blind randomized controlled trial of short-term outcome. Surgery 2000; 127: 276-83

47. Stoppa RE. The treatment of complicated groin and incisional hernias. World J Surg 1989; 13: 545-54

48. Liem MSL, Van der Graaf Y, Van Steensel CJ et al. (1997) Comparison of conventional anterior surgery and laparoscopic surgery for inguinal hernia repair. NEngl J Med, 336, 15417.
49. Neumayer L, Giobbie-Hurder A, Jonasson $O$ et al. (2004) Open mesh versus laparoscopic mesh repair of inguinal hernia. NEngl J Med, 350, 181927.

50. Karthikesalingam SR, Makar SR, Holt PJE, Praseedom RK. Meta-analysis of randomized control trials comparing laparoscopic with open mesh repairof recurrent inguinal inguinal hernia. Br J Surg 2010; 97: 4-7

51. O'Dwyer PJ. Current status of the debate on laparoscopic hernia repair. British Medical Bulletin 2004; 70: 105118

52. International Association for the Study of Pain. Classification of chronic pain. Descriptions of chronic pain syndromes and definitions of pain terms. Prepared by the International Association for the Study of Pain, Subcommittee on Taxonomy. Pain 1986; Suppl 3: S1226.

53. Engelsman AF, van der Mei HC, Ploeg RJ, et al. The phenomenon of infection with abdominal wall reconstruction. Biomaterials 2007; 28: 2314-27.

54. Delikoukos S, Tzovaras G, Liakou P, et al. Late-onset deep mesh infection after inguinal hernia repair. Hernia 2007; 11: 15-7

55. Baur JJ, Harris MT, Kreel I, et al. Twelve year experience with expanded polytetrafluoroethylene in the repair of abdominal wall defects. Mt Sinai J Med 1999;66: 20-5

56. Ridgway DM, Mahmood F, Moore $L$ et al. A blinded randomized trial controlled trial comparing porcine dermal collagen with polypropylene for primary inguinal hernia repair. JACS 2007205 supp 1 page S69

57. Blatnik J, Jin J, Rosen M. Abdominal hernia repair with bridging acellular dermal matrixan expensive hernia sac. Am J Surg 2008; $196: 4750$

58. Bringham S, Conze J, Cuccurullo D, Deprest J, et al. Hernia repair: the search for the ideal meshes. Hernia (2010) 14:8187

59. Wolwacz I Jr, Trindade MRM, Cerski CT. The collagen in transversalis fascia of direct inguinal hernia patients treated by video laparoscopy. Acta Cir Bras 2003; 18: 197-201

60. Burgueson RE. New collagen, new concepts. Annu Rev Cell Biol 1988; 4: 551-7

61. Montes GS. Structural biology of the fibres of the collagenous and elastic systems. Cell Biol Int 1996; 20; 15-27

62. Witte $\mathrm{H}$, Hegelmaier $\mathrm{C}$, Balzer KM, et al. Relevance of the fascia transversalis in inguinal hernia repair using total extraperitoneal plastic reconstruction. Chirurg 1997; 68: 4935

63. Junge $\mathrm{K}$, Klinge $\mathrm{U}$, Rosch $\mathrm{R}$ et al. Decreased collagen type I/III ratio in patients with recurring hernia after implantation of alloplastic prostheses. Langenbecks Arch Surg 2004; 389:1722 